Original Article

\title{
Analysis of glenoid inter-anchor distance with an all-suture anchor system
}

\author{
Jonathan D. Kramer ${ }^{\mathrm{a}}$, Sean Robinson ${ }^{\mathrm{a}, *}$, Connor Purviance ${ }^{\mathrm{b}}$, William Montgomery III $^{\mathrm{a}}$ \\ ${ }^{a}$ St. Mary's Medical Center, San Francisco Orthopedic Residency Program, 450 Stanyan St, San Francisco, CA 94115, United States \\ ${ }^{\mathrm{b}}$ The Taylor Collaboration, 450 Stanyan St, San Francisco, CA 94115, United States
}

\section{A R T I C L E I N F O}

\section{Keywords:}

All-suture anchor

Pull out strength

Biomechanics

Shoulder instability

\begin{abstract}
A B S T R A C T
Background: All-suture anchors used in arthroscopic shoulder stabilization employ small diameter anchors, which allow greater placement density on narrow surfaces such as the glenoid. There is no consensus in the literature about how close to one another two anchors may be implanted.

Purpose: The purpose of the present study is to compare the strength characteristics of two all-suture anchors placed in cadaveric human glenoid at variable distances to one another, in order to determine the minimum distance required for optimal strength.

Methods: Twelve fresh-frozen human cadaveric glenoids were implanted with $1.4 \mathrm{~mm}$ all-suture anchors at varying inter-anchor distances. Each glenoid was used for four tests, for a total of 48 tests. Anchors were implanted adjacent to one another or with 2,3 , or $5 \mathrm{~mm}$ bone bridges between pilot holes. The glenoids then underwent pullout testing using a test frame with a $5 \mathrm{~N}$ preload followed by displacement of $12.5 \mathrm{~mm} / \mathrm{s}$. The primary outcomes were stiffness, failure strength, and ultimate strength.

Results: Stiffness was $13.52 \pm 3.8,17.97 \pm 5.02,17.59 \pm 4.65$ and $18.95 \pm 4.67 \mathrm{~N} / \mathrm{mm}$ for the adjacent, 2 , 3 , and $5 \mathrm{~mm}$ treatment groups, respectively. The adjacent group had a significantly lower stiffness compared to the other treatment groups. Failure strength was $48.68 \pm 20.64,76.16 \pm 23.78,73.19 \pm 35.83$ and $87.04 \pm 34.67 \mathrm{~N}$ for the adjacent, 2, 3, and $5 \mathrm{~mm}$ treatment groups, respectively. The adjacent group had a significantly lower failure strength compared to the other treatment groups. Ultimate strength was also measured to be $190.59 \pm 140.93,268.7 \pm 115.1,283.23 \pm 118.43$, and $291.28 \pm 118.24$ for the adjacent, 2 , 3, and $5 \mathrm{~mm}$ treatment groups, respectively.

Conclusions: This biomechanical study provides evidence that $1.4 \mathrm{~mm}$ all-suture anchors demonstrate similar strength characteristics when placed at least $2 \mathrm{~mm}$ or greater from one another. When $1.4 \mathrm{~mm}$ all-suture anchors were placed adjacent to one another, there was an observed decrease in failure strength and stiffness.

Clinical relevance: This study suggests that $1.4 \mathrm{~mm}$ all-suture anchors may be placed as close as $2 \mathrm{~mm}$ to one another while preserving strength characteristics.
\end{abstract}

\section{Introduction}

Arthroscopic bankart repair using anchor fixation is now one of the most common arthroscopic shoulder surgeries performed. ${ }^{1,2}$ Anchor design has changed significantly since the introduction of the first anchors used for stabilization in $1991 .^{3,4}$ These initial metallic suture anchors were fraught with complications involving interarticular migration of metallic implants as well as distortion of magnetic resonance imaging due to artifact production. ${ }^{5,6}$ This lead to the development of bioabsorbable anchors, followed eventually by all-suture systems in 2010. ${ }^{7,8}$ Advancements in anchor stabilization technique paralleled changes in design. More recently developed anchors are now smaller in size. These smaller anchors may further increase the contact area by allowing many points of fixation. Multiple points of fixation have been postulated to effectively shift the capsule along the entire length of the anterior glenoid in early bankart repair. ${ }^{9}$ In addition, these smaller anchors require smaller drill holes, which decrease the amount of bone removed. In theory, this should allow the surgeon to place a greater number of all-suture anchors into an anatomic region that has minimal real estate, such as the glenoid rim. The Juggerknot Soft Anchor (Zimmer Biomet, Warsaw, IN) is a $1.4 \mathrm{~mm}$ all-suture anchor, which, when deployed, decreases in size vertically but expands laterally, thereby securing the suture anchor against cortical bone. As use of these all-suture anchors increases, an improved understanding of how they can best be utilized may maximize their efficacy and improve clinical outcomes.

\footnotetext{
* Corresponding author.

E-mail addresses: jondkramer@gmail.com, jon.kramer@dignityhealth.org (J.D. Kramer), sean.robinson@dignityhealth.org (S. Robinson), cpurviance@taylorcollaboration.org (C. Purviance), drmonty@netwiz.net (W. Montgomery).
} 
One limiting factor is the proximity of the anchors to one another. Guidelines on anchor spacing tend to be anecdotal and not anchor specific. $^{10,11}$ The purpose of the present study is to compare the strength characteristics of two anchors placed at variable distances to one another, in order to determine the minimum distance required for optimal strength.

\section{Methods}

Twelve fresh-frozen human cadaveric glenoids were obtained from a local tissue bank and thawed $24 \mathrm{~h}$ before testing. The medial border of the scapula was cast into a polyurethane mixture in order to more easily secure to the test frame. The specimens were potted such that the surface of the glenoid was horizontal.

The labrum was initially removed from the potted glenoid with a scalpel. A plate with sets of guide holes (one set per spacing group) was used during testing to maintain proper spacing. The distances between holes were measured between the edges of each hole. The pilot hole was drilled at the edge of the bone-articular margin at approximately $45^{\circ}$ from the horizontal plane. One pilot hole was drilled using the $1.4 \mathrm{~mm}$ drill bit through the guide and into the glenoid. A second pilot hole using a second $1.4 \mathrm{~mm}$ drill bit was then drilled through the guide and into the glenoid while keeping the first drill bit in place in order to ensure spacing was maintained. After both $1.4 \mathrm{~mm}$ holes were drilled, a single orthopedic surgeon deployed two $1.4 \mathrm{~mm}$ all-suture JuggerKnot Soft Anchors in accordance with the manufacturer's instructions. Each anchor was handset by pulling on both suture limbs until the anchor was felt to deploy. Each glenoid was used for a total of four tests, on the anterior, posterior, inferior, and superior regions of the glenoid (as depicted in Fig. 1). Thus a total of 8 anchors were implanted in each glenoid, for a total of 96 anchors. The four regions of the glenoid were randomized to each anchor configuration to account for potential differences in bone density.

After anchor deployment, each specimen was fixed to a test frame (Instron 8521, Instron Inc., Norwood, MA) with the glenoid mounted horizontally (as depicted in Fig. 2). The sutures of each anchor were secured using a clamp made of two aluminum blocks, which were pressed together by two $1 / 2$-inch set screws. The sutures were pulled up over the middle block and down the other side of that middle block. Gauge length was measured to be 10 centimeters. The sutures were held taught as the clamp was tightened. Displacement for both anchors was parallel to the motion of the actuator. A $5 \mathrm{~N}$ preload was applied to the construct; the actuator was placed in displacement control and driven away from the shoulder at a rate of $12.5 \mathrm{~mm} / \mathrm{s}$. Force and displacement were collected from the test frame actuator at a rate of $500 \mathrm{~Hz}$. Single destructive testing was employed. Cyclic testing was not employed, in accordance with previous reports which studied anchor pullout strength and concluded that single destructive testing was sufficient. ${ }^{11-14}$ Pre- and post-test photographs as well as videos were taken for each specimen, and the applicable mode of failure was noted.

\subsection{Statistics}

Stiffness was calculated from the initial linear region of the force displacement curve. Failure strength was defined as the first local maximum or inflection point in the force displacement curve (see Fig. 3). This failure point was calculated using a custom program (MATLAB, Mathworks, Natick, MA) using a $0.2 \mathrm{~mm}$ offset load from the initial linear region. Stiffness was also calculated from the initial linear region of the force displacement curve. Ultimate strength was taken to be the maximum overall load observed. Outcome measures including stiffness, failure strength, and ultimate strength were analyzed by use of student $t$-tests. Statistical analysis was performed using JMP statistical software (SAS, Cary, NC). Statistical significance was set at an $\alpha$ level of 0.05 .

\section{Results}

A total of 48 tests were performed. Twelve tests were performed per spacing group, and each glenoid was used for a total of four tests. 44 failed due to anchor pullout. Two failed due to both sutures tearing. One failed due to one suture tearing and one anchor pullout. Stiffness was $13.52 \pm 3.8,17.97 \pm 5.02,17.59 \pm 4.65$ and $18.95 \pm 4.67 \mathrm{~N} /$ $\mathrm{mm}$ for the adjacent, $2 \mathrm{~mm}, 3 \mathrm{~mm}$ and $5 \mathrm{~mm}$ treatment groups as shown Table 1 . The adjacent group had a significantly lower stiffness compared to the other treatment groups $(\mathrm{p}=<0.05)$. Failure strength was $48.68 \pm 20.64, \quad 76.16 \pm 23.78, \quad 73.19 \pm 35.83$ and $87.04 \pm 34.67 \mathrm{~N}$ for the adjacent, $2 \mathrm{~mm}, 3 \mathrm{~mm}$ and $5 \mathrm{~mm}$ treatment groups as shown in Table 1 . The adjacent group had a significantly lower failure strength compared to the other treatment groups ( $\mathrm{p}=<0.05$ ). Ultimate strength was also measured to be $190.59 \pm 140.93, \quad 268.7 \pm 115.1, \quad 283.23 \pm 118.43, \quad$ and $291.28 \pm 118.24$ for the adjacent, $2 \mathrm{~mm}, 3 \mathrm{~mm}$ and $5 \mathrm{~mm}$ treatment groups as shown in Table 1 . There were no statistically significant differences in ultimate strength. P-values for each of the four treatment groups are shown in Table 3. All four regions of the glenoid exhibited similar values in stiffness, failure strength, and ultimate strength as shown in Table 2. Differences among locations were not statistically significant $(\mathrm{p}=>0.05)$ as seen in Table 4 .

\section{Discussion}

The present study shows that failure strength and stiffness is similar when $1.4 \mathrm{~mm}$ all-suture anchors are implanted $2 \mathrm{~mm}$ apart or greater. However, when placed adjacent to one another, failure strength and stiffness significantly decreased. This is likely due to coalescence of the two drill holes. Statistically significant differences in ultimate strength were not observed even in adjacently placed anchors. This was likely due to sample size.

While there have been studies demonstrating that the use of $1.4 \mathrm{~mm}$ all-suture anchors for labral repair has been promising, we have found no published study providing a threshold of safe proximity between anchors. Clinical results using $1.4 \mathrm{~mm}$ allsuture anchors for labral repair have been promising. Agrawal et al published a study on a series of eighteen patients undergoing arthroscopic repair using $1.4 \mathrm{~mm}$ allsuture anchors and reported full return to sports. These anchors were placed between $5 \mathrm{~mm}$ and $10 \mathrm{~mm}$ apart. ${ }^{15}$ Despite this possibly commonly used rule-of-thumb, there is no evidence suggesting that small diameter all-suture anchors require $5-10 \mathrm{~mm}$ of spacing to ensure maximum strength characteristics.

In another study by Dwyer et al, maximum load to failure and tensile displacement of an all-suture glenoid anchor was compared with a traditional screw-in glenoid anchor. ${ }^{14}$ There was no difference between maximum load to failure in glenoid bone, though the handset allsuture anchor displayed early displacement and greater laxity. However, pre-tensioning the all-suture anchor to $60 \mathrm{~N}$ eliminated this behavior.

Mazzocca et al compared the use of the same $1.4 \mathrm{~mm}$ JuggerKnot anchor used in the present study to a traditional solid anchor in a biomechanical analysis. ${ }^{16}$ There was no statistical difference detected in displacement or maximum load to failure. However, they did note a significantly lower load required to cause $2 \mathrm{~mm}$ of labral displacement when compared to the solid anchor, which they hypothesized to be caused by displacement of the all-suture anchor in the pilot hole.

In addition to their similar strength characteristics as traditional anchors, small all-suture anchors may have the advantage of lessened interference with advanced imaging, as well as fewer reactive bony changes. In a retrospective analysis by Willemot et al, 58 anchors were implanted in 20 patients for shoulder instability and subsequently assessed at minimum 1-year follow-up. ${ }^{17}$ Postoperative magnetic resonance imaging (MRI) showed minimal cyst formation around implanted anchors, with 45 anchors showing no reactive bony changes. 


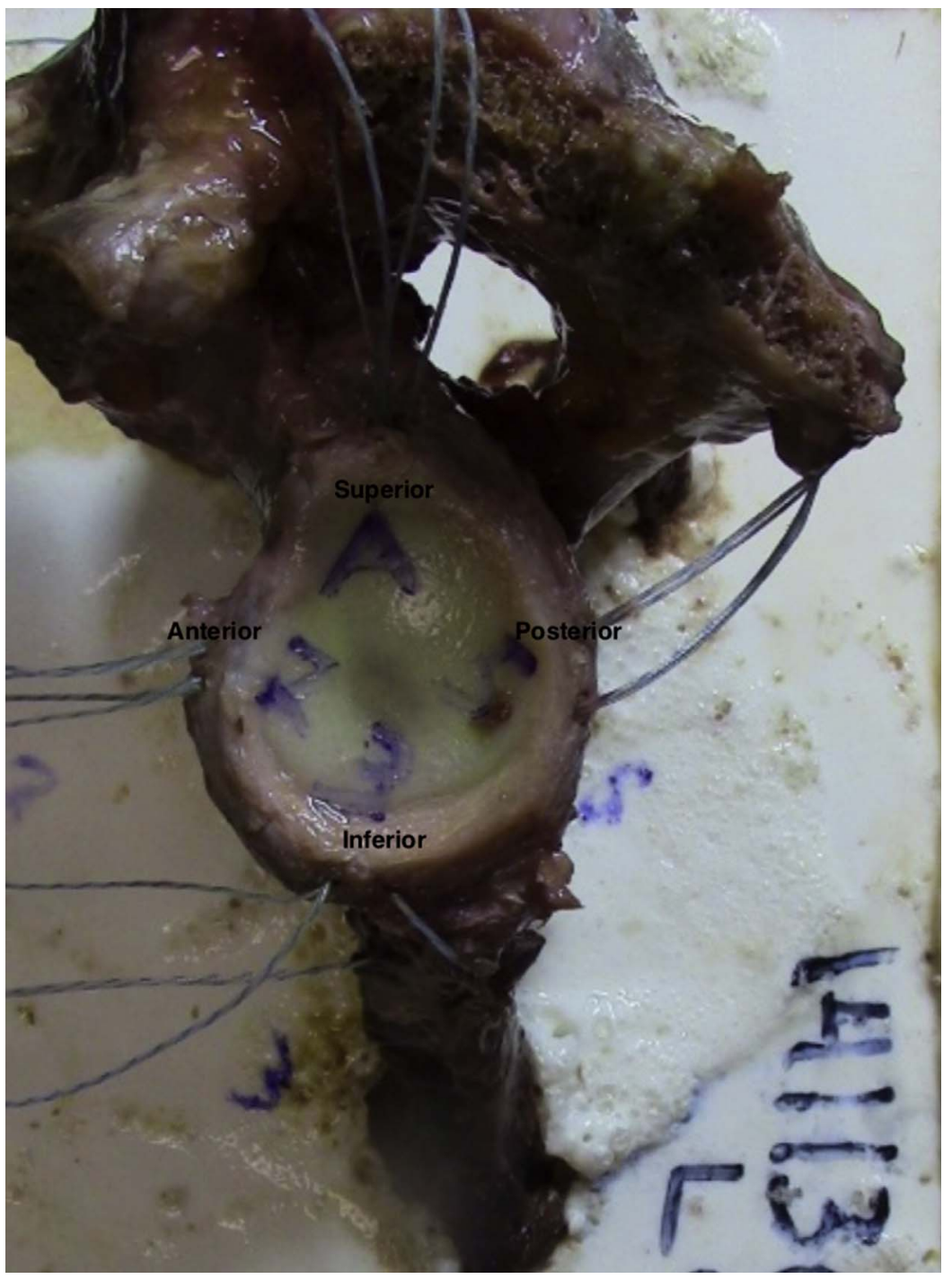

Fig. 1. Glenoid face demonstrating the four regions used for testing (anterior, superior, posterior, inferior).

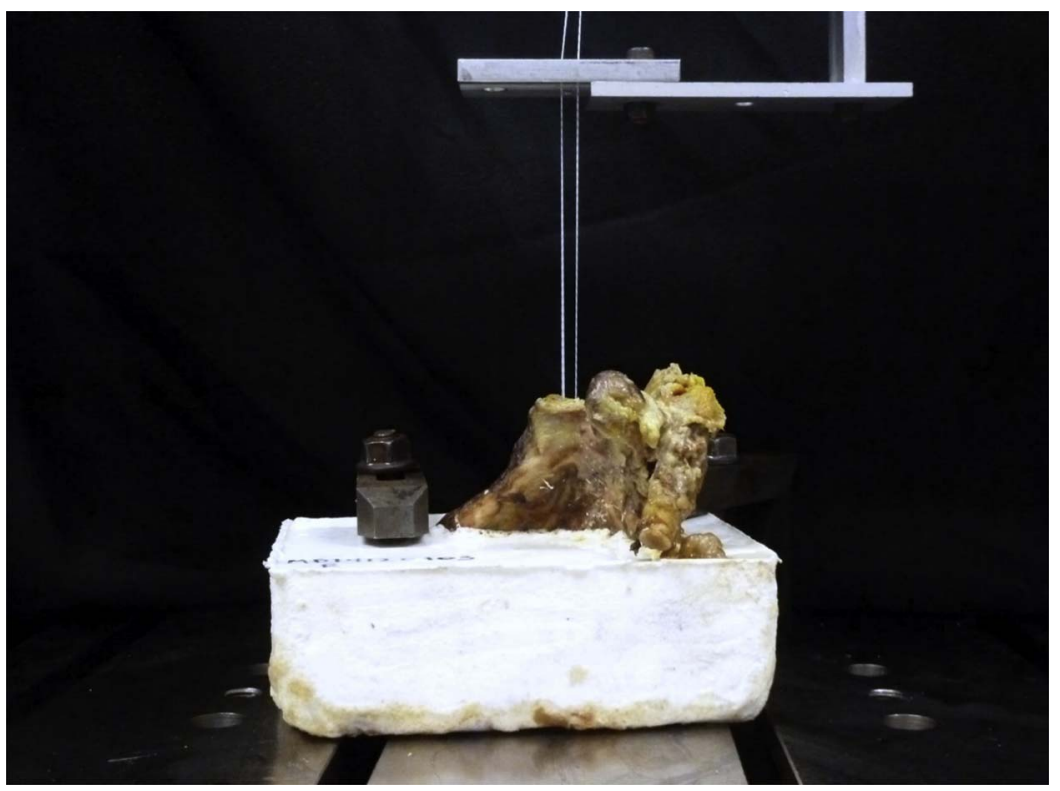

Fig. 2. The testing apparatus is shown here. The scapula was potted to a polyurethane mixture then secured with the glenoid face parallel to the horizon. The two suture limbs were secured to the test frame with a clamp made two aluminum blocks, which were pressed together by two $1 / 2$-inch setscrews. Direction of pull was perpendicular to face of the glenoid. 


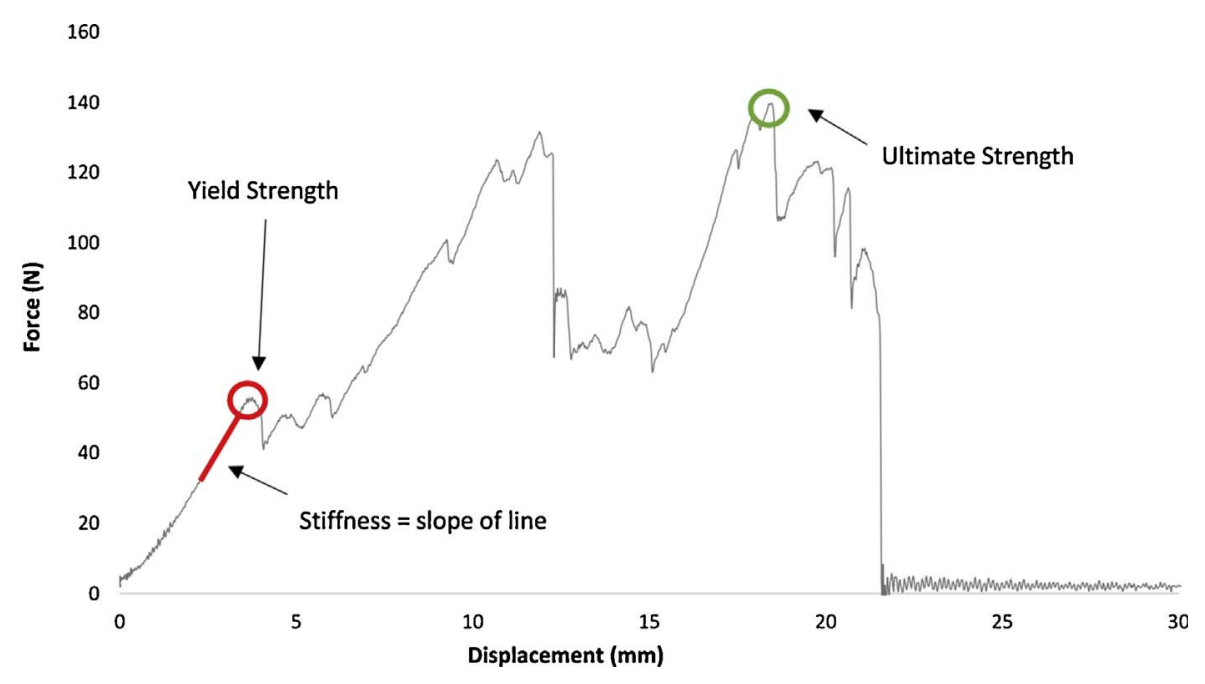

Fig. 3. A graph demonstrating yield strength, stiffness, and ultimate strength. Yield strength was defined as the first local maximum. Stiffness was calculated from the initial linear region of the force displacement curve. Ultimate strength was taken to be the maximum overall load observed.

Table 1

Stiffness, yield strength, and ultimate strength data in tabulated format for each of the four treatment groups.

\begin{tabular}{|c|c|c|c|c|c|c|c|c|c|c|c|c|}
\hline \multirow[b]{2}{*}{ Anchor Spacing } & \multicolumn{4}{|c|}{ Stiffness (N/mm) } & \multicolumn{4}{|c|}{ Yield Strength (N) } & \multicolumn{4}{|c|}{ Ultimate Strength (N) } \\
\hline & Mean & SD & Range & $95 \% \mathrm{CI}$ & Mean & SD & Range & $95 \% \mathrm{CI}$ & Mean & SD & Range & $95 \% \mathrm{CI}$ \\
\hline $\operatorname{ADJ}(\mathrm{n}=12)$ & 13.52 & 3.80 & $6.75-19.72$ & 2.15 & 48.68 & 20.61 & $20.48-89.05$ & 11.66 & 190.59 & 140.93 & $38.04-509.85$ & 79.74 \\
\hline $2 \mathrm{~mm}(\mathrm{n}=12)$ & 17.97 & 5.02 & $8.59-26.79$ & 2.84 & 76.16 & 23.78 & $34.65-108.24$ & 13.45 & 268.70 & 115.10 & $120.5-472.5$ & 65.12 \\
\hline $3 \mathrm{~mm}(\mathrm{n}=12)$ & 17.59 & 4.65 & $11.49-29.31$ & 2.63 & 73.19 & 35.83 & $40.08-176.41$ & 20.27 & 283.23 & 118.43 & $151.41-553.12$ & 67.01 \\
\hline $5 \mathrm{~mm}(\mathrm{n}=12)$ & 18.95 & 4.67 & $9.86-28.28$ & 2.64 & 87.04 & 34.67 & $53.48-174.29$ & 19.62 & 291.28 & 118.24 & $94.32-441.19$ & 66.9 \\
\hline
\end{tabular}

$\mathrm{N}=\mathrm{N}, \mathrm{mm}=$ millimeter, $\mathrm{CI}=$ Confidence Interval; $\mathrm{SD}=$ Standard Deviation; $\mathrm{ADJ}=$ Adjacent.

Table 2

Stiffness, yield strength, and ultimate strength in tabulated format for each of the four regions on the glenoid.

\begin{tabular}{|c|c|c|c|c|c|c|c|c|c|c|c|c|}
\hline \multirow[b]{2}{*}{ Glenoid Position } & \multicolumn{4}{|c|}{ Stiffness $(\mathrm{N} / \mathrm{mm})$} & \multicolumn{4}{|c|}{ Yield Strength (N) } & \multicolumn{4}{|c|}{ Ultimate Strength (N) } \\
\hline & Mean & SD & Range & $95 \% \mathrm{CI}$ & Mean & SD & Range & $95 \% \mathrm{CI}$ & Mean & SD & Range & $95 \% \mathrm{CI}$ \\
\hline Posterior $(n=12)$ & 18.99 & 5.04 & $11.66-28.28$ & 2.85 & 79.28 & 36.04 & $42.51-174.29$ & 20.39 & 290.62 & 129.14 & $118.4-553.12$ & 73.06 \\
\hline Anterior $(\mathrm{n}=12)$ & 17.23 & 5.82 & $9.86-29.31$ & 3.29 & 74.40 & 38.02 & $25.6-176.41$ & 21.51 & 273.28 & 142.15 & $94.32-509.85$ & 80.43 \\
\hline Superior $(\mathrm{n}=12)$ & 16.58 & 3.86 & $10.45-24.7$ & 2.18 & 65.07 & 25.62 & $20.48-108.26$ & 14.49 & 260.49 & 127.60 & $43.91-450.17$ & 72.19 \\
\hline Inferior $(\mathrm{n}=12)$ & 15.23 & 4.42 & $6.75-21.9$ & 2.50 & 66.33 & 28.00 & $22.26-117.92$ & 15.84 & 209.41 & 104.58 & $38.04-441.19$ & 59.17 \\
\hline
\end{tabular}

$\mathrm{N}=\mathrm{N}, \mathrm{mm}=$ millimeter, $\mathrm{CI}=$ Confidence Interval; $\mathrm{SD}=$ Standard Deviation; $\mathrm{ADJ}=$ Adjacent.

Table 3

Anchor Spacing: P-values showing significant differences between different spacing treatment groups. P values less than 0.05 are in bold.

\begin{tabular}{|c|c|c|c|c|c|c|c|c|c|c|c|c|}
\hline & \multicolumn{4}{|c|}{ Stiffness } & \multicolumn{4}{|c|}{ Failure Strength } & \multicolumn{4}{|c|}{ Ultimate Strength } \\
\hline & ADJ & $2 \mathrm{~mm}$ & $3 \mathrm{~mm}$ & $5 \mathrm{~mm}$ & ADJ & $2 \mathrm{~mm}$ & $3 \mathrm{~mm}$ & $5 \mathrm{~mm}$ & ADJ & $2 \mathrm{~mm}$ & $3 \mathrm{~mm}$ & $5 \mathrm{~mm}$ \\
\hline ADJ & - & - & - & - & - & - & - & - & - & - & - & - \\
\hline $2 \mathrm{~mm}$ & 0.02 & - & - & - & 0.03 & - & - & - & 0.13 & - & - & - \\
\hline $3 \mathrm{~mm}$ & 0.03 & 0.84 & - & - & 0.05 & 0.81 & - & - & 0.07 & 0.77 & - & - \\
\hline $5 \mathrm{~mm}$ & 0.01 & 0.60 & 0.47 & - & 0.00 & 0.37 & 0.26 & - & 0.05 & 0.66 & 0.87 & - \\
\hline
\end{tabular}

Significance set at $\mathrm{p}<0.05 . \mathrm{mm}=$ millimeter; ADJ $=$ Adjacent.

Though the present study suggests that all-suture anchors may be placed in close proximity to one another, the surgeon must be aware of the risk for glenoid rim fracture. Banaerjee et al describe several cases of patients treated with absorbable suture anchor reconstruction who subsequently developed recurrent instability due to glenoid rim fracture. ${ }^{18}$ In these cases, revision arthroscopy was not possible and patients were revised with a modified Latarjet procedure. The risk of "postage stamp" fracture is something to consider when placing many small anchors within close proximity to each other.

The main limitation of this study is that it is an in vitro biomechanical study in a dry environment at room temperature. Thus the physiological processes that may otherwise influence shoulder mechanics, tissue healing, and implant incorporation were not present here. Furthermore, biomechanical loading was perpendicular to the glenoids, whereas in the human shoulder, physiological loading is dynamic and repair constructs are stressed from various angles. ${ }^{19}$ This study is also limited by the fact that different glenoids are likely to have different bone densities. ${ }^{20}$ No bone density studies were performed and matched pairs were not used. However, regions of the glenoid were randomized to each treatment group and there was no significant 
Table 4

Anchor location: P-values comparing stiffness, failure strength, and ultimate strength between each location on the glenoid. No p values were less than 0.05 .

\begin{tabular}{|c|c|c|c|c|c|c|c|c|c|c|c|c|}
\hline & \multicolumn{4}{|l|}{ Stiffness } & \multicolumn{4}{|c|}{ Failure Strength } & \multicolumn{4}{|c|}{ Ultimate Strength } \\
\hline & Anterior & Inferior & Posterior & Superior & Anterior & Inferior & Posterior & Superior & Anterior & Inferior & Posterior & Superior \\
\hline Anterior & - & - & - & - & - & - & - & - & - & - & - & - \\
\hline Inferior & 0.32 & - & - & - & 0.54 & - & - & - & 0.22 & - & - & - \\
\hline Posterior & 0.38 & 0.06 & - & - & 0.71 & 0.33 & - & - & 0.74 & 0.12 & - & - \\
\hline Superior & 0.75 & 0.50 & 0.23 & - & 0.48 & 0.92 & 0.29 & - & 0.81 & 0.33 & 0.56 & - \\
\hline
\end{tabular}

Significance set at $\mathrm{p}<0.05 . \mathrm{mm}=$ millimeter; $\mathrm{ADJ}=$ Adjacent.

difference in strength characteristics based on glenoid region.

\section{Conclusion}

In summary, this biomechanical study provides evidence that $1.4 \mathrm{~mm}$ all-suture anchors demonstrate similar strength characteristics when placed at greater or equal to $2 \mathrm{~mm}$ apart from one another. When $1.4 \mathrm{~mm}$ all-suture anchors were placed adjacent to one another, there was a measured decrease in failure strength and stiffness. This information can be useful for clinicians performing arthroscopic labral repair in a clinical scenario that calls for multiple points of fixation in close proximity.

\section{Conflicts of interest}

The author declares no conflicts of interest.

\section{Funding}

Funding for this project was provided by The Taylor Collaboration and the San Francisco Orthopedic Residency Program.

\section{References}

1. Diduch DR, Scanelli J, Tompkins M, Milewski MD, Carson E, Ma S-Y. Tissue anchor use in arthroscopic glenohumeral surgery. J Am Acad Orthop Surg. 2012;20:459-471 Richard.

2. Owens BD, Harrast JJ, Hurwitz SR, Thompson TL, Wolf JM. Surgical trends in Bankart repair: an analysis of data from the American Board of Orthopaedic Surgery certification examination. Am J Sports Med. 2011;39:1865-1869.

3. Wolf EM, Wilk RM, Richmond JC. Arthroscopic Bankart repair using suture anchors. Oper Tech Orthop. 1991;1:184-191.

4. Dhawan A, Ghodadra N, Karas V, Salata MJ, Cole BJ. Complications of bioabsorbable suture anchors in the shoulder. Am J Sports Med. 2012;40:1424-1430.
5. Silver MD, Daigneault JP. Symptomatic interarticular migration of glenoid suture anchors. Arthrosc J Arthrosc Relat Surg. 2000;16:102-105.

6. Ozbaydar M, Elhassan B, Warner JJP. The use of anchors in shoulder surgery: a shift from metallic to bioabsorbable anchors. Arthrosc J Arthrosc Relat Surg. 2007;23:1124-1126.

7. Cole BJ, Provencher MT. Safety profile of bioabsorbable shoulder anchors. Arthrosc $J$ Arthrosc Relat Surg. 2007;23:912-913.

8. Barber FA, Snyder SJ, Abrams JS, Fanelli GC, Savoie FH. Arthroscopic bankart reconstruction with a bioabsorbable anchor. J Shoulder Elbow Surg. 2003;12:535-538.

9. Torchia ME, Caspari RB, Asselmeier MA, Beach WR, Gayari M. Arthroscopic transglenoid multiple suture repair: 2 to 8 year results in 150 shoulders. Arthrosc J Arthrosc Relat Surg. 1997;13:609-619.

10. Barber FA, Feder SM, Burkhart SS, Ahrens J. The relationship of suture anchor failure and bone density to proximal humerus location: a cadaveric study. Arthrosc J Arthrosc Relat Surg. 1997;13:340-345.

11. Barber FA, Herbert MA. Cyclic loading biomechanical analysis of the pullout strengths of rotator cuff and glenoid anchors: 2013 update. Arthrosc J Arthrosc Relat Surg. 2013;29:832-844.

12. Leedle BP, Miller MD. Pullout strength of knotless suture anchors. Arthrosc J Arthrosc Relat Surg. 2005;21:81-85.

13. Barber FA, Herbert MA, Hapa O, et al. Biomechanical analysis of pullout strengths of rotator cuff and glenoid anchors: 2011 update. Arthrosc J Arthrosc Relat Surg. 2011;27:895-905.

14. Dwyer T, Willett TL, Dold AP, et al. Maximum load to failure and tensile displacement of an all-suture glenoid anchor compared with a screw-in glenoid anchor. Knee Surg Sports Traumatol Arthrosc. 2016;24:357-364.

15. Agrawal V, Pietrzak W. Triple labrum tears repaired with the JuggerKnot ${ }^{\mathrm{TM}}$ soft anchor: technique and results. Int J Shoulder Surg. 2015;9:81.

16. Mazzocca AD, Chowaniec D, Cote MP, et al. Biomechanical evaluation of classic solid and novel all-soft suture anchors for glenoid labral repair. Arthrosc $J$ Arthrosc Relat Surg. 2012;28:642-648.

17. Willemot L, Elfadalli R, Jaspars KC, et al. Radiological and clinical outcome of arthroscopic labral repair with all-suture anchors. Acta Orthop Belg. 2016;82:174-178.

18. Banerjee S, Weiser L, Connell D, Wallace AL. Glenoid rim fracture in contact athletes with absorbable suture anchor reconstruction. Arthrosc J Arthrosc Relat Surg. 2009;25:560-562.

19. Wetzler MJ, Bartolozzi AR, Gillespie MJ, et al. Fatigue properties of suture anchors in anterior shoulder reconstructions: Mitek GII. Arthrosc J Arthrosc Relat Surg. 1996;12:687-693.

20. Kalouche I, Crépin J, Abdelmoumen S, Mitton D, Guillot G, Gagey O. Mechanical properties of glenoid cancellous bone. Clin Biomech Bristol Avon. 2010;25:292-298. 